\title{
Prediction of early hepatocellular carcinoma recurrence using germinal center kinase-like kinase
}

\author{
Cheng-Hsun Ho ${ }^{1,2, *}$, Huai-Chia Chuang ${ }^{3, *}$, I-Chin Wu ${ }^{2}$, Hung-Wen Tsai, ${ }^{4,5}$, Yh-Jyh \\ Lin', Hung-Yu Sun7, Kung-Chia Young7, Yen-Cheng Chiu' ${ }^{2}$, Pin-Nan Cheng ${ }^{2}$, Wen- \\ Chun Liu ${ }^{2,5}$, Tse-Hua Tan ${ }^{3,8}$, Ting-Tsung Chang ${ }^{2,5,9}$ \\ ${ }^{1}$ Research Center of Clinical Medicine, National Cheng Kung University Hospital, College of Medicine, National Cheng Kung \\ University, Tainan, Taiwan \\ ${ }^{2}$ Department of Internal Medicine, National Cheng Kung University Hospital, College of Medicine, National Cheng Kung \\ University, Tainan, Taiwan \\ ${ }^{3}$ Immunology Research Center, National Health Research Institutes, Zhunan, Taiwan \\ ${ }^{4}$ Department of Pathology, National Cheng Kung University Hospital, College of Medicine, National Cheng Kung University, \\ Tainan, Taiwan \\ ${ }^{5}$ Infectious Disease and Signaling Research Center, National Cheng Kung University, Tainan, Taiwan \\ ${ }^{6}$ Department of Surgery, National Cheng Kung University Hospital, College of Medicine, National Cheng Kung University, \\ Tainan, Taiwan \\ ${ }^{7}$ Department of Medical Laboratory Science and Biotechnology, College of Medicine, National Cheng Kung University, Tainan, \\ Taiwan \\ ${ }^{8}$ Department of Pathology \& Immunology, Baylor College of Medicine, Houston, Texas, USA \\ ${ }^{9}$ Institute of Molecular Medicine, College of Medicine, National Cheng Kung University, Tainan, Taiwan \\ *These authors have contributed equally to this work \\ Correspondence to: Ting-Tsung Chang, email: ttchang@mail.ncku.edu.tw \\ Tse-Hua Tan, email: ttan@nhri.org.tw
}

Keywords: hepatocellular carcinoma, recurrence, GLK, NFKB

Received: September 08, $2015 \quad$ Accepted: June 04, 2016

Published: June 20, 2016

\section{ABSTRACT}

Germinal center kinase-like kinase (GLK) is a key controller of autoimmunity. In this study, we assessed the clinical relevance and tumorigenic effects of GLK in hepatocellular carcinoma (HCC). Using immunohistochemistry, we showed that the GLK proportion score increased in both cancerous and adjacent non-cancerous liver tissue from patients with HCC recurrence. A Kaplan-Meier analysis revealed that patients with a wide distribution of GLK in non-cancerous liver tissue had a higher rate of HCC recurrence than those with very low or no GLK expression. Multivariate Cox regression analyses indicated that a high GLK proportion score in non-cancerous liver tissue was an independent predictor of early HCC recurrence after resection. Lentiviral vector-mediated overexpression of GLK activated the nuclear factor kappa B (NFKB) signaling cascade and accelerated cell cycle progression in primary human hepatocytes, thereby promoting proliferation. An increase in GLK expression coincided with NFKB activation and enhanced expression of proliferating cell nuclear antigen in HCC tissue. Our findings demonstrate a potential hepatocarcinogenic effect of GLK and the feasibility of using GLK to predict early HCC recurrence.

\section{INTRODUCTION}

Hepatocellular carcinoma (HCC) is the third most common cause of cancer-related deaths globally [1]. There are approximately three quarters of a million new cases of HCC and 700,000 deaths from HCC each year. Risk factors for $\mathrm{HCC}$ include chronic hepatitis B virus (HBV) or hepatitis $\mathrm{C}$ virus (HCV) infection, alcoholic liver disease, and non-alcoholic fatty liver disease [2,3]. Advances in imaging techniques for early detection, surgical methods, and the development of novel therapies have drastically improved the prognosis of patients with $\mathrm{HCC}$ and 
minimized complications $[4,5]$. However, the high rate of recurrence following hepatic resection substantially reduces the overall survival of patients. The average fiveyear cumulative rate of $\mathrm{HCC}$ recurrence is greater than $70 \%$ globally $[6,7]$. Relapse is the major cause of death of HCC patients but the factors that drive HCC recurrence are incompletely understood. Therefore, it is imperative to identify a marker for predicting early recurrence and patient prognosis, and for facilitating the optimal clinical management of patients following hepatectomy.

Germinal center kinase-like kinase (GLK/MAP4K3), a member of the mitogen-activated protein kinase kinase kinase kinase (MAP4K) family of proteins, is a Ste20-like serinethreonine kinase [8]. GLK has a conserved, N-terminal kinase domain, a conserved C-terminal citron homology domain, and multiple proline-rich motifs in the central region of the protein. It modulates the mammalian target of rapamycin (mTOR) complex 1 after treatment with amino acids [9, 10] and determines cell death through post-transcriptional regulation of $\mathrm{BH} 3$-only proteins [11]. GLK also stimulates the protein kinase $\mathrm{C}$ (PKC)- $\theta$-dependent nuclear factor kappa $\mathrm{B}(\mathrm{NF} \kappa \mathrm{B})$ signaling pathway in T cells, and this activity is directly correlated with the severity of systemic lupus erythematosus [12]. GLK regulates various cellular processes, however its role in cancer development and recurrence is unclear. In this study, we investigated the clinical relevance of GLK in early HCC recurrence, and elucidated the effects of GLK activity on hepatocyte proliferation.

\section{RESULTS}

\section{Patient characteristics}

The demographic and clinical data for 69 patients with HCC are shown in Table 1 . There was a $3: 1$ ratio of men to women. Approximately one-fifth of the patients were dependent on alcohol or smoking. Thirty percent of the patients had been diagnosed with fatty liver and $38 \%$ with liver cirrhosis. More than $50 \%$ of the patients had HBV and more than 30\% had HCV. Histology data indicated that patients had slight hepatic necroinflammation and moderate fibrosis. Patients had increased serum alanine aminotransferase, aspartate aminotransferase, and $\alpha$-fetoprotein levels, but normal albumin, total bilirubin, and prothrombin times. Based on the TNM classification of malignant tumors, 22 patients were categorized as stage one, 36 as stage two, and 11 as stage three. Thirty-two patients were diagnosed with HCC recurrence during post-hepatectomy follow-up. These patients had lower albumin levels $(P=0.002)$, advanced-stage tumors $(P<0.001)$, and higher mortality rates $(P=0.044)$ than those without recurrence (Table 1$)$.

\section{GLK is associated with $\mathrm{HCC}$ recurrence}

We evaluated the expression level and pattern of GLK in resected HCC tissue. Immunohistochemical analysis revealed that GLK expression was higher in cancerous tissue compared to adjacent non-cancerous tissue (Figure 1A). In addition, patients with recurrent HCC had similar GLK levels in cancerous liver tissue but higher GLK levels in non-cancerous tissue compared to patients who did not have recurrent HCC. Imaging at higher magnification indicated that GLK was predominantly expressed in the cytoplasm of hepatocytes. Western blot analyses of HCC tissue extracts confirmed that GLK was overexpressed in cancerous liver tissues (Figure 1B and 1C). Cancerous tissue generally had higher GLK proportion scores and higher Allred scores, but the GLK intensity scores were similar compared to adjacent non-cancerous tissue (Table 2). The proportion but not the intensity of GLK expression in non-cancerous liver tissues was associated with $\mathrm{HCC}$ recurrence.

We next investigated factors associated with GLK expression in HCC tissue. Patients with different GLK proportion scores in cancerous tissue had similar degrees of necroinflammation and fibrosis. They also had similar incidences of HBV infection, HCV infection, steatosis, and liver cirrhosis (Supplementary Table 1). However, the GLK proportion score in non-cancerous liver tissue was correlated with the HCC recurrence rate. These results indicated that GLK was widely distributed in malignant liver tissues and in non-malignant liver cells of patients with $\mathrm{HCC}$ recurrence.

\section{GLK activates NFKB signaling in human hepatocytes}

We previously demonstrated that GLK induces PKC- $\theta$ phosphorylation at Thr538 and hyperactivation of $\mathrm{NF} \kappa \mathrm{B}$, which is crucial for the progression of $\mathrm{T}$ helper (Th) 17 cell-mediated autoimmune disease [12]. Here, we examined whether GLK activated this signaling pathway in hepatocytes. GLK overexpression resulted in the activation of NFKB signaling as evidenced by increased I $\mathrm{KB}$ kinase (IKK) phosphorylation and p65 nuclear translocation but not PKC- $\theta$ phosphorylation in primary human hepatocytes (Figure 2A). GLK and phospho-IKK were observed in similar areas of serial sections of HCC tissue from equivalent biopsies (Figure 2B panel). Malignant tissue had higher phospho-IKK proportion scores compared to paired non-cancerous tissue samples from HCC patients, and showed a similar expression pattern to that of GLK in HCC tissue (Figure $2 \mathrm{C}$, left). Furthermore, patients with recurrent HCC had higher IKK phosphorylation in non-cancerous tissue than patients who did not have recurrence (Figure $2 \mathrm{C}$, right). Nevertheless, PKC- $\theta$ phosphorylation at Thr538 in HCC tissues was not correlated with GLK or IKK phosphorylation (Supplementary Figure S1A). Additionally, the levels of Th17-related cytokines including interleukin (IL)-1 $\beta$, IL-6, IL-17, and tumor necrosis factor- $\alpha$ in serum were not correlated with the proportion or intensity of GLK (Supplementary Figure 
Table 1: Characteristics of patients with hepatocellular carcinoma $(n=69)$

\begin{tabular}{|c|c|c|c|c|}
\hline Variable & Total $(n=69)$ & Recurrence $(n=32)$ & Non-recurrence $(n=37)$ & $P$-value \\
\hline $\operatorname{Sex}(M: F)$ & $51: 18$ & $24: 8$ & $27: 10$ & 1.000 \\
\hline Age (years) & $60.2 \pm 10.9$ & $60.3 \pm 8.5$ & $60.2 \pm 12.7$ & 0.971 \\
\hline Body mass index & $24.6 \pm 3.4$ & $24.5 \pm 4.1$ & $24.7 \pm 2.8$ & 0.785 \\
\hline Alcohol & $18.8 \%(13 / 69)$ & $15.6 \%(5 / 32)$ & $21.6 \%(8 / 37)$ & 0.556 \\
\hline Smoking & $21.7 \%(15 / 69)$ & $15.6 \%(5 / 32)$ & $27.0 \%(10 / 37)$ & 0.381 \\
\hline Fatty liver & $30.4 \%(21 / 69)$ & $18.8 \%(6 / 32)$ & $40.5 \%(15 / 37)$ & 0.068 \\
\hline HBsAg $(+)$ & $55.1 \%(38 / 69)$ & $59.4 \%(19 / 32)$ & $51.4 \%(19 / 37)$ & 0.628 \\
\hline HCV RNA (+) & $27.5 \%(19 / 69)$ & $37.5 \%(12 / 32)$ & $24.3 \%(9 / 37)$ & 0.298 \\
\hline $\begin{array}{l}\operatorname{HBsAg}(+) \text { and } \mathrm{HCV} \\
\operatorname{RNA}(+)\end{array}$ & $2.9 \%(2 / 69)$ & $3.1 \%(1 / 32)$ & $2.7 \%(1 / 37)$ & 1.000 \\
\hline $\begin{array}{l}\text { Knodell inflammation } \\
\text { score }\end{array}$ & $3.7 \pm 2.0$ & $4.1 \pm 1.7$ & $3.4 \pm 2.2$ & 0.131 \\
\hline Ishak fibrosis score & $4.0 \pm 1.7$ & $4.4 \pm 1.7$ & $3.6 \pm 1.6$ & 0.056 \\
\hline Liver cirrhosis & $37.7 \%(26 / 69)$ & $50 \%(16 / 32)$ & $27.0 \%(10 / 37)$ & 0.080 \\
\hline $\operatorname{ALT}(\mathrm{U} / \mathrm{L})$ & $53.2 \pm 38.5$ & $62.3 \pm 42.6$ & $45.3 \pm 33.2$ & 0.067 \\
\hline $\mathrm{AST}(\mathrm{U} / \mathrm{L})$ & $53.4 \pm 31.9$ & $60.1 \pm 33.8$ & $47.6 \pm 29.4$ & 0.104 \\
\hline $\operatorname{Albumin}(\mathrm{g} / \mathrm{dL})$ & $4.4 \pm 0.3$ & $4.3 \pm 0.3$ & $4.6 \pm 0.3$ & 0.002 \\
\hline Total bilirubin (mg/dL) & $0.7 \pm 0.4$ & $0.7 \pm 0.2$ & $0.8 \pm 0.4$ & 0.143 \\
\hline $\begin{array}{l}\text { Prolongation of } \\
\text { prothrombin time }(\mathrm{sec})\end{array}$ & $0.6 \pm 0.7$ & $0.7 \pm 0.7$ & $0.6 \pm 0.7$ & 0.436 \\
\hline Creatinine $(\mathrm{mg} / \mathrm{dL})$ & $1.2 \pm 1.2$ & $1.5 \pm 1.7$ & $0.9 \pm 0.4$ & 0.086 \\
\hline$\alpha$-fetoprotein $(\mathrm{ng} / \mathrm{mL})$ & $425.9 \pm 1219.4$ & $589.6 \pm 1469.6$ & $284.2 \pm 950.9$ & 0.303 \\
\hline TNM stage $(1: 2: 3)$ & $22: 36: 11$ & $7: 14: 11$ & $15: 22: 0$ & $<0.001^{\mathrm{a}}$ \\
\hline Follow up time (days) & $928 \pm 347$ & $877.7 \pm 373.7$ & $970.8 \pm 320.7$ & 0.269 \\
\hline Mortality & $10.1 \%(7 / 69)$ & $18.8 \%(6 / 32)$ & $2.7 \%(1 / 37)$ & 0.044 \\
\hline
\end{tabular}

Data are percentage or mean (standard deviation). Abbreviations: ALT, alanine aminotransferase; AST, aspartate aminotransferase; HBsAg, hepatitis B virus surface antigen; HCV, hepatitis C virus. A 2-tailed independent $t$ test was used for continuous variables between recurrence and non-recurrence groups. Comparisons of nominal values were by Fisher's exact test except TNM stage. ${ }^{a}$ By a Pearson Chi square test.

S1B). These results revealed that GLK-mediated NFKB activation in HCC was independent of the PKC- $\theta-$ Th17 signaling pathway.

\section{GLK enhances primary hepatocyte proliferation}

GLK stimulated cell cycle progression, which was reflected by a decrease in the percentage of cells in the G0/G1 phases and an increase in the percentage of cells in the $\mathrm{S}$ and $\mathrm{G} 2 / \mathrm{M}$ phases, and accelerated primary human hepatocyte proliferation (Figure 3A and 3B). Proliferating cell nuclear antigen (PCNA) and cyclin-dependent kinase 2, two essential regulators of the G1/S phase, were increased by GLK in primary human hepatocytes. In addition, PCNA expression was correlated with GLK expression in HCC tissue (Figure 3D). These results indicated that GLK had a proliferative effect on human hepatocytes.

\section{The proportion of GLK in non-cancerous liver tissue predicts early $\mathrm{HCC}$ recurrence}

Kaplan-Meier analyses revealed that patients who had a GLK proportion score $\geq 2$ in non-cancerous liver tissue (Log-rank test, $P=0.031$ ) or an advanced tumor 

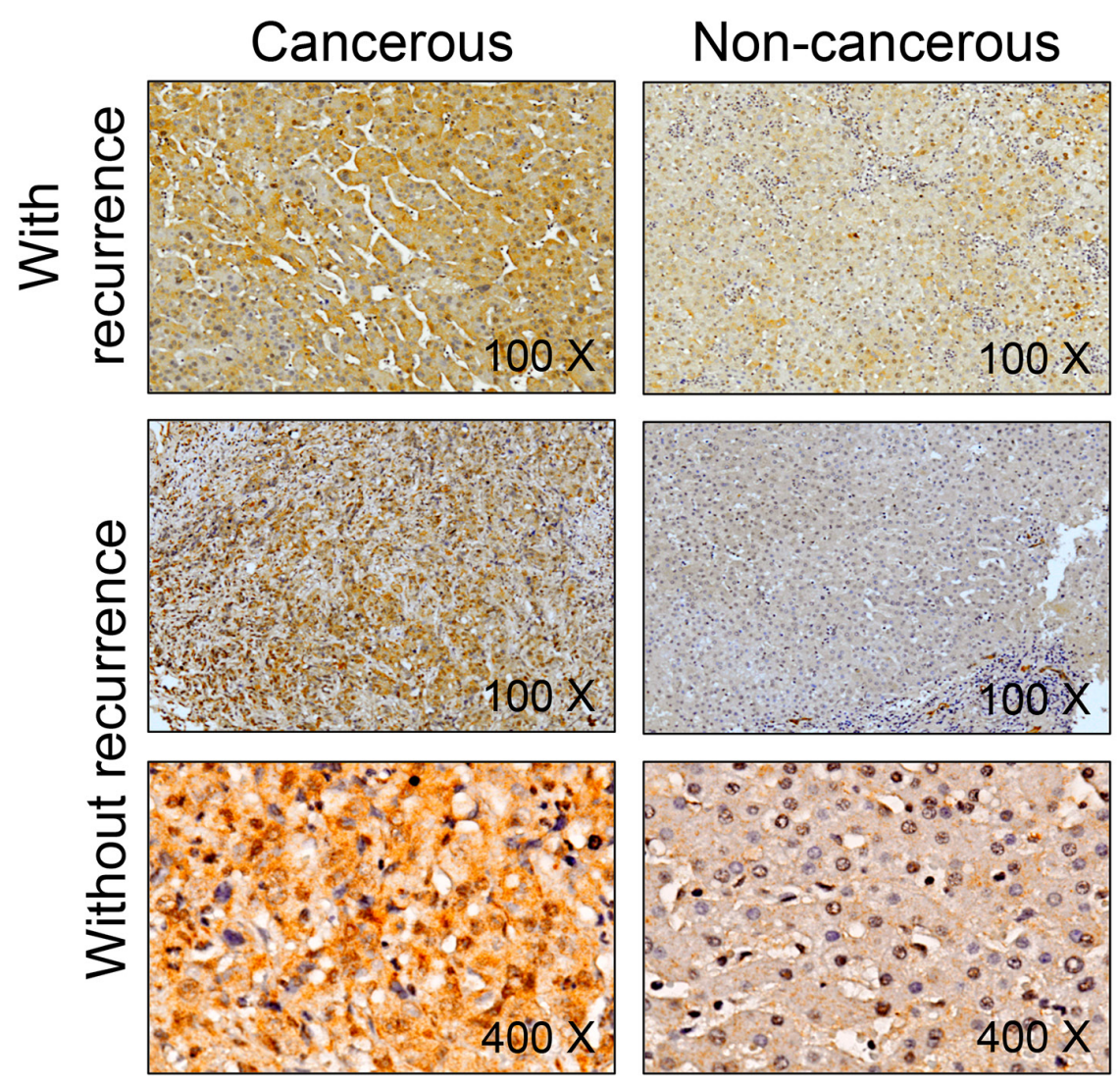

$B$

C
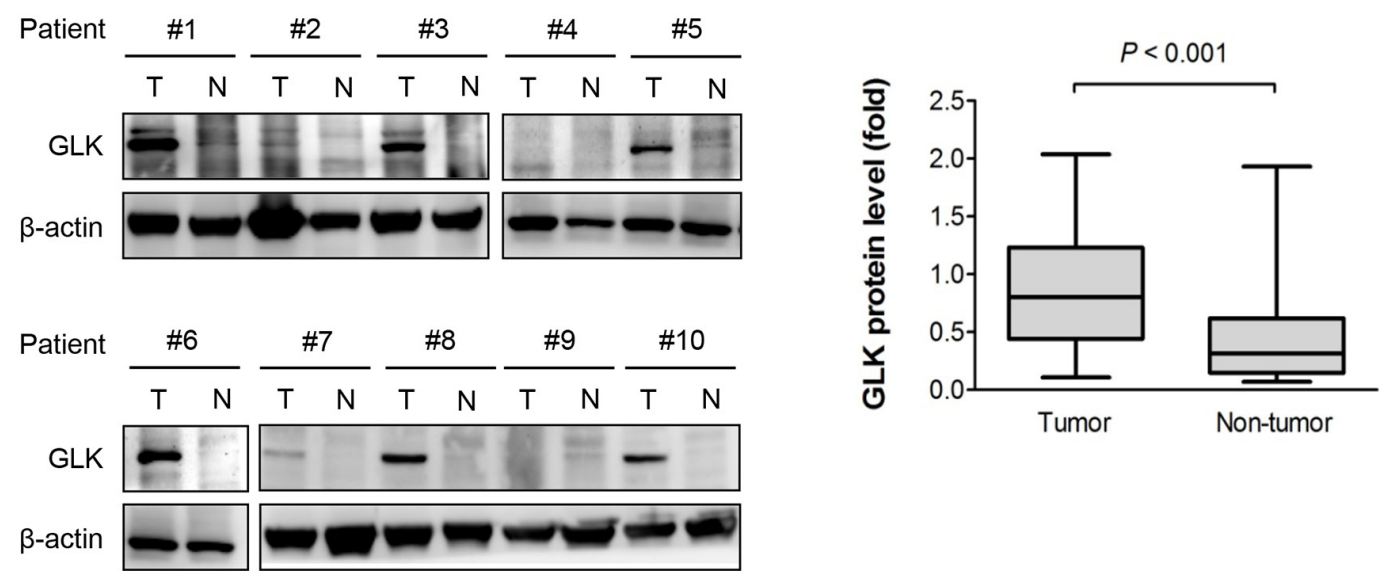

Figure 1: GLK is overexpressed in HCC. A. Immunohistochemistry results from representative sections demonstrate overexpression of GLK in cancerous and adjacent non-cancerous paired liver tissue samples from patients with recurrent HCC. At higher magnification $(\times$ $400)$, the cellular distribution of GLK in hepatocytes is visualized. B. GLK in extracts generated from tumorigenic (T) and adjacent nontumorigenic $(\mathrm{N})$ tissue was detected by immunoblotting. C. Comparison of GLK protein levels from the immunoblotting results $(\mathrm{n}=30)$ between cancerous and adjacent non-cancerous tissue shown as box-and-whisker plots (minimum, first quartile, median, third quartile, and maximum). Relative fold changes are normalized to $\beta$-actin. The $P$-value was obtained from the Mann-Whitney $U$ test. 
Table 2: GLK expression in liver tissues of patients with HCC

\begin{tabular}{|c|c|c|c|c|c|c|c|c|c|}
\hline \multirow{2}{*}{$\begin{array}{l}\text { GLK } \\
\text { expression }\end{array}$} & \multirow{2}{*}{$\begin{array}{c}\text { Cancerous } \\
(\mathrm{n}=69)\end{array}$} & \multirow{2}{*}{$\begin{array}{c}\text { Non- } \\
\text { cancerous } \\
(\mathrm{n}=69)\end{array}$} & \multirow[t]{2}{*}{$P$-value ${ }^{1}$} & \multicolumn{2}{|c|}{ Cancerous } & \multirow[t]{2}{*}{$P$-value ${ }^{2}$} & \multicolumn{2}{|c|}{ Non-cancerous } & \multirow[t]{2}{*}{$P$-value } \\
\hline & & & & $\begin{array}{l}\text { Recurrence } \\
\quad(\mathrm{n}=\mathbf{3 2})\end{array}$ & $\begin{array}{c}\text { Non- } \\
\text { recurrence } \\
(\mathbf{n}=\mathbf{3 7})\end{array}$ & & $\begin{array}{c}\text { Recurrence } \\
\quad(\mathrm{n}=32)\end{array}$ & $\begin{array}{l}\text { Non- } \\
\text { recurrence } \\
(\mathbf{n}=\mathbf{3 7})\end{array}$ & \\
\hline $\begin{array}{l}\text { Intensity } \\
\text { score }(0-3)\end{array}$ & $1.0 \pm 1.0$ & $0.9 \pm 0.8$ & 0.187 & $1.1 \pm 0.9$ & $1.0 \pm 1.0$ & 0.448 & $1.1 \pm 0.8$ & $0.7 \pm 0.9$ & 0.057 \\
\hline $\begin{array}{l}\text { Proportion } \\
\text { score }(0-5)\end{array}$ & $1.5 \pm 1.4$ & $1.1 \pm 1.0$ & 0.017 & $1.6 \pm 1.2$ & $1.5 \pm 1.5$ & 0.882 & $1.4 \pm 1.0$ & $0.8 \pm 1.0$ & 0.029 \\
\hline $\begin{array}{l}\text { Allred } \\
\text { score }(0-8)\end{array}$ & $2.6 \pm 2.2$ & $1.9 \pm 1.8$ & 0.033 & $2.7 \pm 1.9$ & $2.5 \pm 2.4$ & 0.667 & $2.4 \pm 1.6$ & $1.5 \pm 1.8$ & 0.028 \\
\hline
\end{tabular}

The intensity score is graded on scale from 0 to 3 ( 0 for no staining, 1 for weak staining, 2 for moderated staining, and 3 for strong staining). The proportion score is graded on a scale from 0-5 ( 0 for no staining, 1 for $\geq 1 \%, 2$ for $\geq 10 \%, 3$ for $\geq 33.3 \%, 4$ for $\geq 66.7 \%$, and 5 for $100 \%$ ). Allred score (range $0-8)=$ intensity score + proportion score. Data are shown as mean \pm standard deviation. $P$-values ${ }^{1}$ are from 2 -tailed paired $t$ tests. $P$-values ${ }^{2}$ and $P$-values ${ }^{3}$ are from 2 -tailed independent $t$ tests.

stage (Log-rank test $P<0.001$ ), but not with chronic HBV infection, chronic HCV infection, liver cirrhosis, or fatty liver, had a significantly lower recurrence-free survival rate than their counterparts (Figure 4A, panel). Multivariate Cox regression analyses showed that high GLK proportion scores in non-cancerous liver tissue as well as TNM stage were independent factors strongly linked to early HCC recurrence (Table 3). The percentage of GLK expression in non-cancerous liver tissue was inversely correlated ( $r=$ $-0.413, P=0.019)$ with recurrence time in 32 patients with recurrent HCC (Figure 4B). The overall survival rates in patients with different GLK proportion scores were similar (Figure 4C).

\section{DISCUSSION}

We performed a comparative analysis of the GLK expression pattern (GLK signature) in cancerous and adjacent non-cancerous tissue in order to better understand HCC development and recurrence. We found that GLK was a marker of HCC, and that a broad distribution of GLK in non-malignant hepatocytes determined HCC recurrence. In vitro studies revealed that GLK had a proliferative effect on primary human hepatocytes. Thus, therapeutic strategies that target GLK may be effective for the treatment of HCC patients who have undergone hepatic resection.

GLK is a key regulator of $\mathrm{T}$ cell receptor signaling pathways and is critical for $\mathrm{T}$ cell functions. Indeed, GLK-knockout mice were shown to have impaired T cell proliferation, differentiation, and immune activation [12]. Upon T cell receptor signal transduction, GLK interacts with its upstream adaptor SLP-76, phosphorylates PKC- $\theta$, and triggers downstream NFKB activation. Hyperactivation of this signaling cascade induces IL-17 production and contributes to the progression of autoimmune disorders such as systemic lupus erythematosus and adult-onset Still's disease $[12,15]$. GLK also functions in other cell types. For example, it activates endophilin-mediated JunN-terminal kinase in human embryonic kidney 293 cells [16], mTOR signaling to modulate HeLa cell growth and viability [17], and post-transcriptionally regulates $\mathrm{BH} 3-$ only proteins to regulate cell death in human osteosarcoma cells [11]. These data suggest that GLK is a crucial regulator of cell growth and death.

Here, we demonstrated that GLK promotes cell cycle progression and hepatocyte proliferation, which may contribute to hepatocarcinogenesis. Importantly, a GLK proportion score $\geq 2$, which was indicative of GLK expression by more than $10 \%$ of non-tumorigenic hepatocytes, was linked to early HCC recurrence. This finding suggested that a small amount of GLK could have a strong oncogenic effect on hepatocytes, and that GLK was important for HCC recurrence. However, our assessment of GLK-related effects on the overall survival of HCC patients was limited by the low mortality rate and relatively short follow-up duration in this study. Furthermore, better management of HCC patients and medical interventions that prolonged the overall life-span of patients weakened the association between tumor recurrence and mortality. Therefore, similar survival rates were observed between patients with high and low GLK expression. Long-term follow-up studies are therefore required to assess the impact of GLK on HCC patient survival.

$\mathrm{NF} \kappa \mathrm{B}$ is critical for the cellular response to proinflammatory stimuli, and it links chronic inflammation to carcinogenesis [18-20]. NFאB can contribute to carcinogenesis [21-23] through its ability to regulate cell proliferation, apoptosis, immortalization, migration, and invasion [24-27]. It also has a critical role in the progression of hepatitis to HCC [28]. Most patients in our study had chronic viral hepatitis and $30 \%$ had been 
A

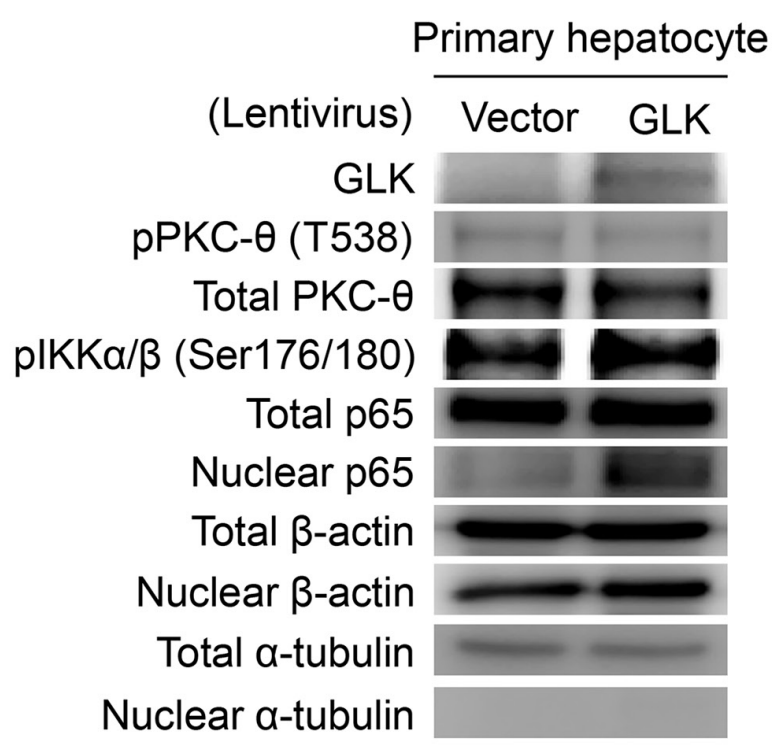

B

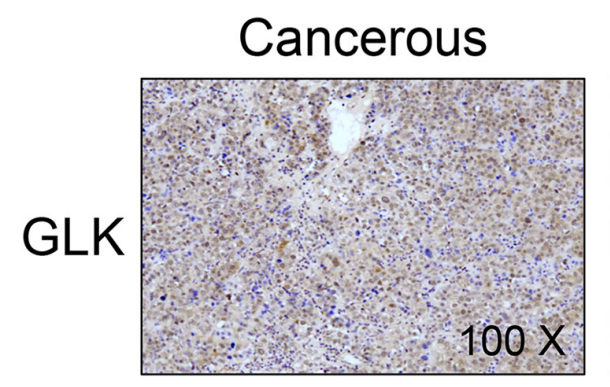

Non-cancerous
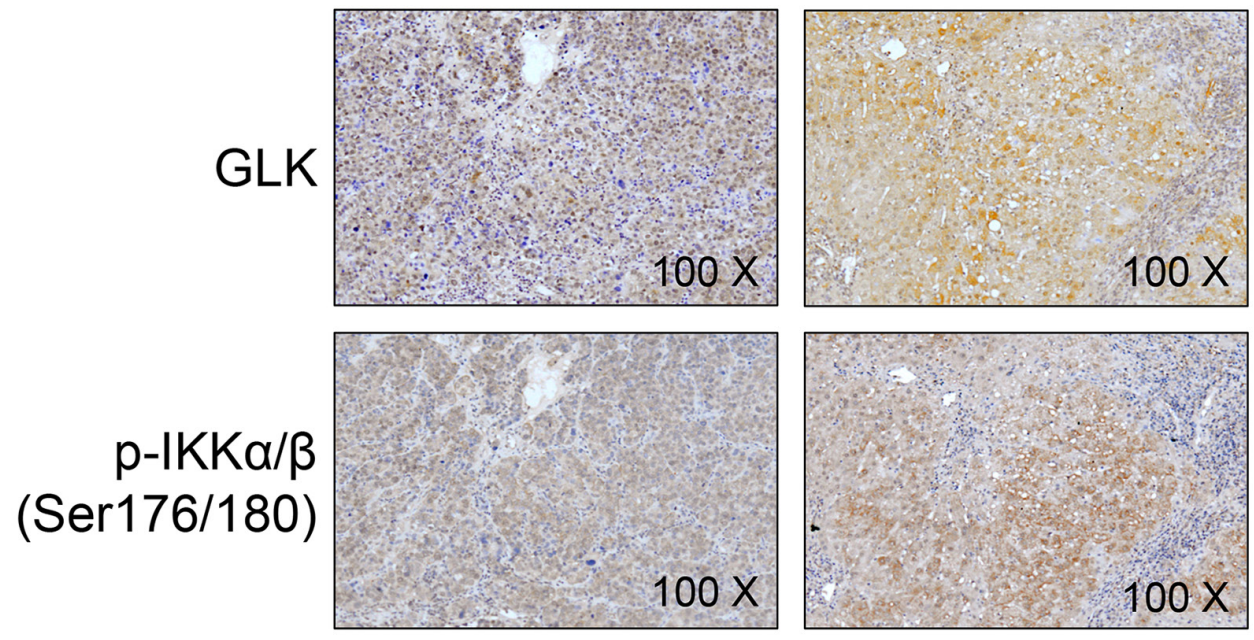

C
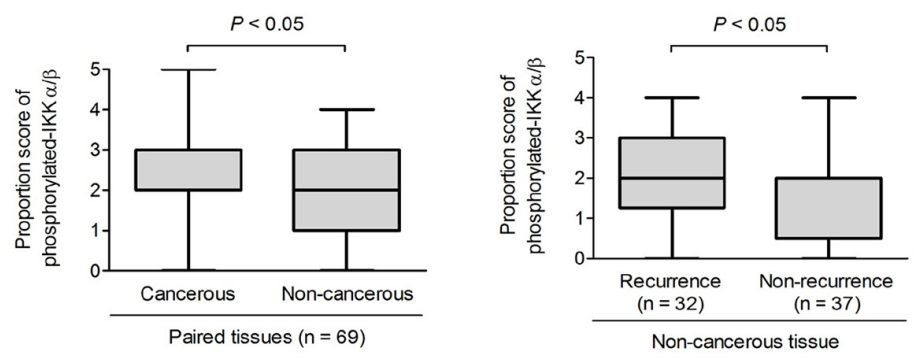

Figure 2: GLK induces PKC- $\boldsymbol{\theta}$-independent activation of NFкB. A. Immunoblotting to detect PKC- $\theta$ phosphorylation and $\mathrm{NF \kappa B}$ activation in primary human hepatocytes 48 hours after recombinant lentivirus infection. B. Detection of GLK and phosphorylated $\mathrm{IKK} \alpha / \beta(\operatorname{Ser} 176 / 180)$ in cancerous and non-cancerous HCC tissue using immunohistochemistry. C. Comparisons of the proportion scores of phosphorylated IKK $\alpha / \beta$ between cancerous tissue and adjacent non-cancerous tissue (left), and non-cancerous liver tissue from patients with or without recurrent HCC (right), are shown as box-and-whisker plots (minimum, first quartile, median, third quartile, and maximum). The $P$-values in the left and right figures were obtained from Wilcoxon signed-rank and Mann-Whitney $U$ tests, respectively. 


\section{$A$}
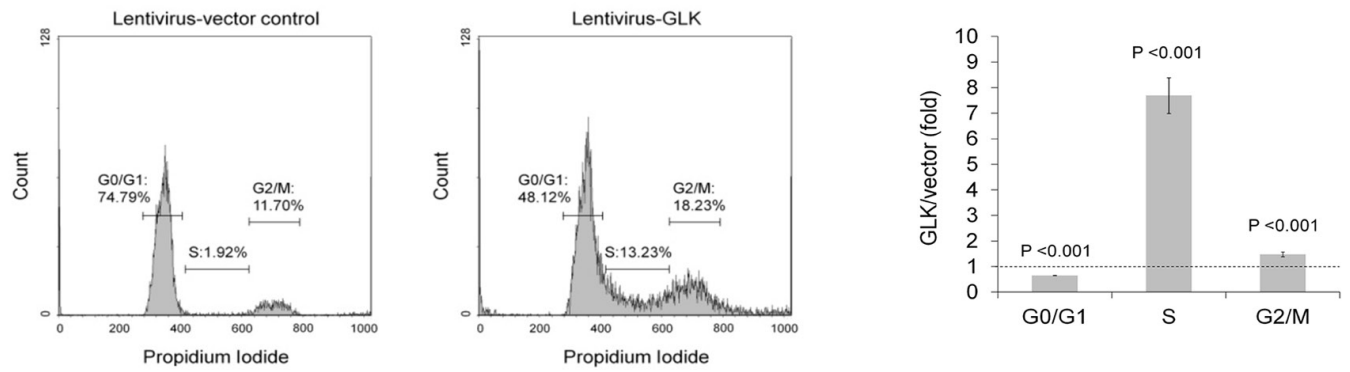

$B$

C
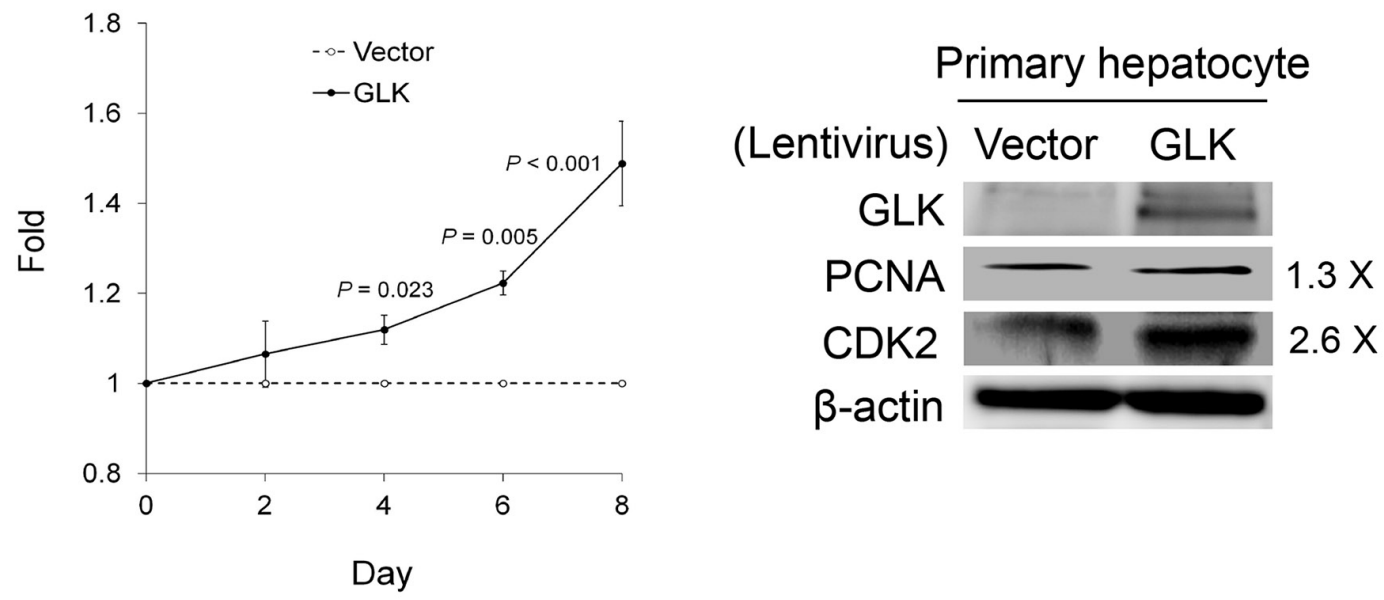

$D$
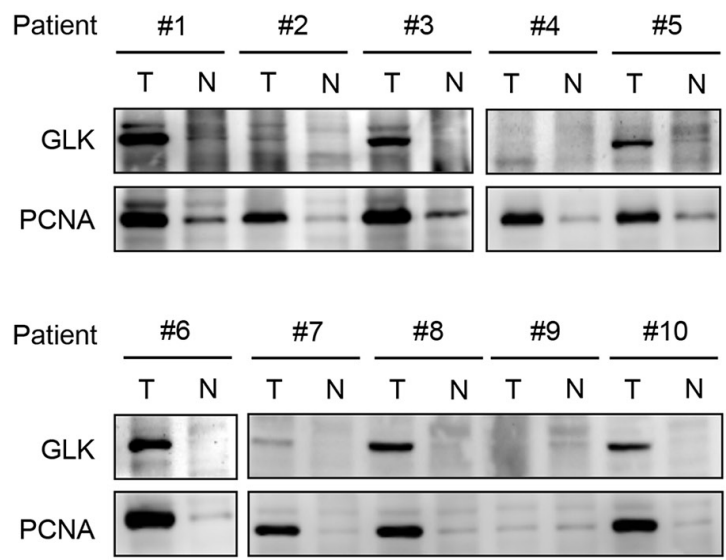

Figure 3: GLK modulates cell cycle progression in hepatocytes. A. The cell cycle status of primary human hepatocytes with or without GLK overexpression was analyzed using propidium iodide staining and flow cytometry. B. Fold change in the proliferation of primary human hepatocytes with or without GLK overexpression was measured in triplicate and calculated at days 2, 4, 6, and 8 . $P$-values were obtained from two-tailed independent $t$-tests. C. Levels of cell cycle markers in primary human hepatocytes detected using immunoblotting. D. Co-expression of GLK and PCNA in the same HCC tissue extracts as in Figure 1B. T, tumorigenic tissue; N, adjacent, non-tumorigenic tissue. 

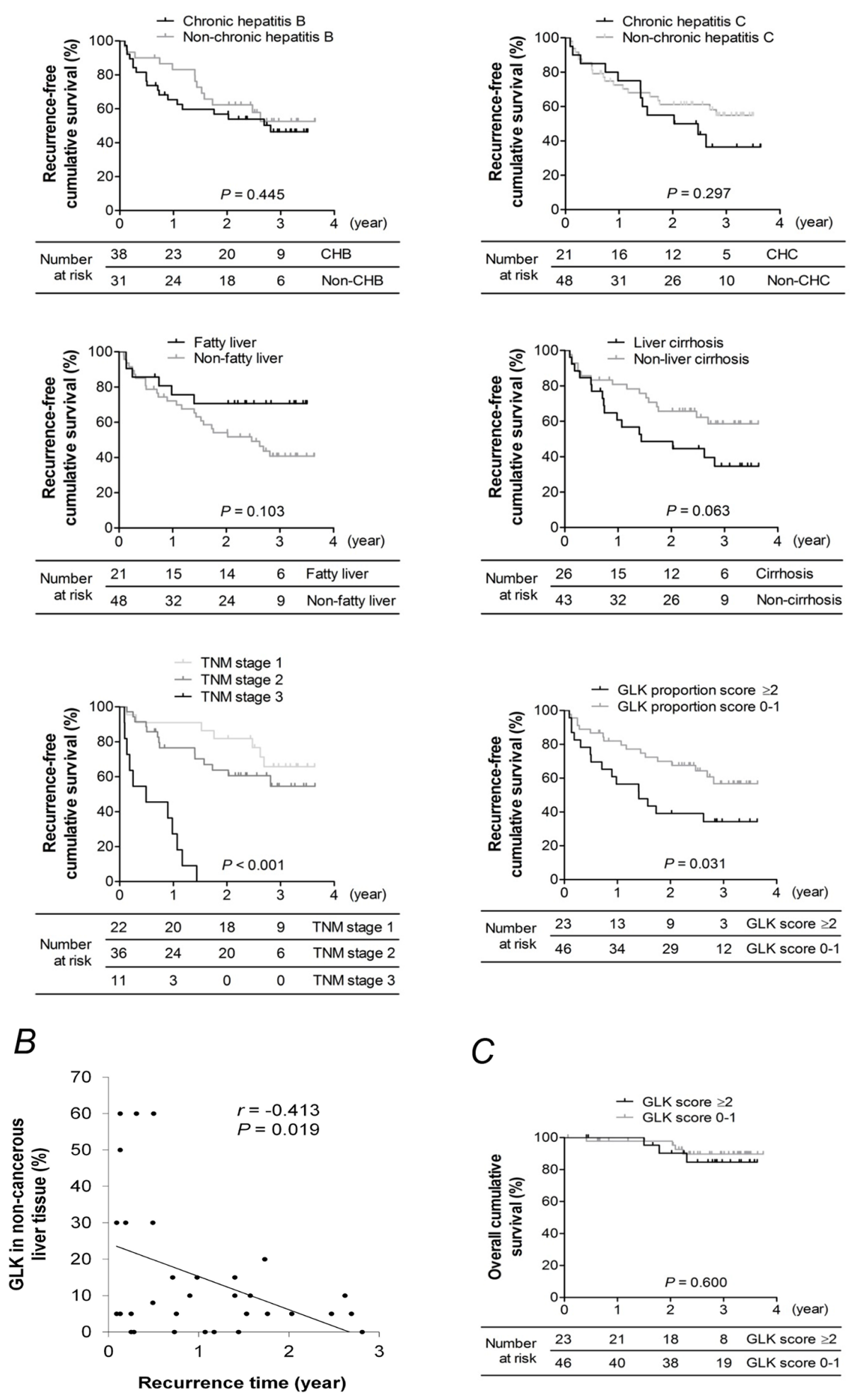

Figure 4: Kaplan-Meier analysis. A. Recurrence-free survival rates for patients with or without chronic hepatitis B, chronic hepatitis C, liver cirrhosis, fatty liver, advanced TNM stage, or a GLK proportion score $\geq 2$ in adjacent non-cancerous liver tissue. B. Correlation between the percentage of GLK expression in non-cancerous liver tissue and time of HCC recurrence. The coefficient $r$ was obtained from Pearson's correlation test. C. Overall survival of patients with a GLK proportion score $\geq 2$ or $<2$ in adjacent non-cancerous liver tissue. $P$-values in (A) and (C) were obtained from log-rank tests. 
Table 3: Multivariate Cox regression analysis of $\mathrm{HCC}$ recurrence

\begin{tabular}{|c|c|c|c|c|c|c|}
\hline \multirow[t]{2}{*}{ Variable } & \multicolumn{2}{|c|}{ Within 1 year } & \multicolumn{2}{|c|}{ Within 2 years } & \multicolumn{2}{|l|}{ Overall } \\
\hline & $\begin{array}{c}\text { Hazard ratio } \\
(95 \% \text { CI })\end{array}$ & $P$-value & $\begin{array}{c}\text { Hazard ratio } \\
(95 \% \text { CI })\end{array}$ & $P$-value & $\begin{array}{c}\text { Hazard ratio } \\
(95 \% \text { CI })\end{array}$ & $P$-value \\
\hline Sex & $0.05(0.01-0.36)$ & 0.003 & $0.22(0.06-0.80)$ & 0.021 & $0.61(0.12-3.18)$ & .554 \\
\hline Age & $1.05(0.97-1.14)$ & 0.208 & $1.03(0.97-1.09)$ & 0.348 & $1.03(0.96-1.11)$ & .384 \\
\hline Alcohol & $0.18(0.01-2.83)$ & 0.221 & $0.29(0.06-1.54)$ & 0.147 & $0.74(0.06-8.51)$ & .809 \\
\hline Smoking & $0.30(0.03-4.32)$ & 0.314 & $0.76(0.20-2.81)$ & 0.675 & $0.44(0.05-3.85)$ & .462 \\
\hline Fatty liver & $1.13(0.30-4.32)$ & 0.854 & $0.48(0.18-1.29)$ & 0.145 & $0.26(0.06-1.21)$ & .087 \\
\hline HBV infection & $13.16(1.07-162.15)$ & 0.044 & $2.55(0.73-8.88)$ & 0.142 & $2.41(0.34-16.82)$ & .376 \\
\hline HCV infection & $15.74(1.08-229.90)$ & 0.044 & $3.14(0.74-13.26)$ & 0.119 & $1.93(0.23-15.86)$ & .541 \\
\hline Liver cirrhosis & $0.84(0.25-2.84)$ & 0.783 & $1.20(0.46-3.09)$ & 0.711 & $3.93(0.74-20.86)$ & .108 \\
\hline$\alpha$-fetoprotein & $1.00(1.00-1.00)$ & 0.632 & $1.00(1.00-1.00)$ & 0.671 & $1.00(1.00-1.00)$ & .740 \\
\hline TNM stage & $11.31(3.13-40.94)$ & $<0.001$ & $7.71(3.17-18.74)$ & $<0.001$ & $5.77(1.77-18.82)$ & .004 \\
\hline $\begin{array}{l}\text { GLK proportion } \\
\text { score in non- } \\
\text { cancerous tissue }\end{array}$ & $2.59(1.33-5.02)$ & 0.005 & $2.18(1.38-3.44)$ & $<0.001$ & $3.06(1.45-6.49)$ & .003 \\
\hline $\begin{array}{l}\text { pIKK proportion } \\
\text { score in non- } \\
\text { cancerous tissue }\end{array}$ & $0.98(0.62-1.52)$ & 0.913 & $1.24(0.87-1.77)$ & 0.233 & $2.22(1.16-4.26)$ & .017 \\
\hline
\end{tabular}

Abbreviations: CI, confidence interval; HBV, hepatitis B virus; HCC, hepatocellular carcinoma; HCV, hepatitis C virus; pIKK, phosphorylated inhibitor of nuclear factor kappa B kinase.

diagnosed with steatohepatitis. Persistent liver inflammation in these patients probably contributed to a robust $\mathrm{NF \kappa B}$ activation. In vitro analyses demonstrated that cell cycle progression and increased PCNA were accompanied by

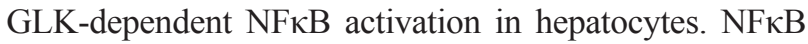
hyperactivity [29-31] and PCNA [32-34] have been shown to be essential for HCC recurrence. Therefore, a GLKNFкB-cell proliferation axis may exist in the liver. PKC- $\theta$ is a pivotal mediator that connects GLK-NFKB signaling in T cells (with the exception of the liver) [12]. Moreover, the expression of Th17-related cytokine was not correlated with GLK expression. Therefore, GLK may bypass PKC- $\theta$ to stimulate NFKB activity in the liver.

An enhancement in kinase activity is a common phenomenon in various cancers. Sorafenib inhibits the activity of multiple tyrosine kinases. It is currently the standard of care for advanced HCC owing to its efficacy in prolonging overall survival and extending the duration of tumor progression in patients [35]. Unfortunately, a global phase III randomized, doubleblind, placebo-controlled trial reported that adjuvant sorafenib after resection or ablation did not reduce the recurrence rate [36]. In this study, we demonstrated the clinical significance of GLK in HCC recurrence. The development of new therapeutics that target GLK would therefore improve HCC patient outcomes.

\section{MATERIALS AND METHODS}

\section{Patients}

This retrospective study was approved by the Institutional Review Board of the National Cheng Kung University Hospital (No B-ER-101-259). Resected liver tissue, clinical information, and laboratory data for 69 patients with HCC were obtained from the Tissue Bank and database at the Research Center of Clinical Medicine, National Cheng Kung University Hospital. All patients were negative for human immunodeficiency virus and autoimmune diseases.

\section{Antibodies}

The rabbit anti-GLK antibody that was used for immunohistochemical analysis was purchased from LTK BioLaboratories (Taoyuan, Taiwan). Rabbit antibodies to detect GLK, protein kinase C (PKC)- $\theta$, phosphorylated (Ser176/180)-IKK $\alpha / \beta$, and the NFאB p65 subunit by western blotting were purchased from Cell Signaling Technology (Danvers, MA, USA). The rabbit antiphospho (Threonine 538)-PKC- $\theta$ antibody was purchased from Thermo Fisher Scientific (Waltham, MA, USA). The rabbit anti-proliferating cell nuclear antigen (PCNA) 
antibody and horseradish peroxidase-conjugated goat anti-mouse and anti-rabbit antibodies were purchased from Abcam (Cambridge, UK). The rabbit anti-cyclindependent kinase (CDK) 2 antibody was purchased from Santa Cruz Biotechnology (Dallas, TX, USA). Finally, mouse antibodies to detect human $\beta$-actin and $\alpha$-tubulin were purchased from Sigma-Aldrich (St. Louis, MO, USA).

\section{Lentivirus-mediated gene transfer}

The lentiviral vector pReceiver-LV105 containing full-length GLK coding sequence (NM 003618.3) was purchased from GeneCopoeia (Rockville, MD, USA). The packaging plasmid pCMVdeltaR8.91 and VSV-G expression plasmid pMD.G were obtained from the National RNAi Core Facility, Academia Sinica, Taiwan. We co-transfected the GLK-lentiviral construct or control lentiviral vector with the pCMVdeltaR8.91 and pMD.G plasmids into $293 \mathrm{~T}$ cells to generate recombinant lentiviruses. Culture medium was collected 48 hours posttransfection, sterilized using a syringe filter with a 0.22 $\mu \mathrm{m}$ pore size hydrophilic polyethersulfone membrane, and concentrated using ultracentrifugation. Primary human hepatocytes that were purchased and maintained in Hepatocyte Medium (ScienCell Research Laboratories, Carlsbad, CA, USA) were incubated with recombinant lentiviruses for 48 hours in the presence of $8 \mu \mathrm{g} / \mathrm{mL}$ polybrene (Sigma-Aldrich).

\section{Immunohistochemistry}

Formalin fixed, paraffin-embedded tissue sections were de-paraffinized, rehydrated, and heated in $10 \mathrm{mM}$ sodium ( $\mathrm{pH}$ 6.0) for antigen retrieval. Hydroxy peroxide (3\% in methanol) and blocking reagent were used to minimize endogenous peroxidase activity and nonspecific signals. Tissue sections were then incubated with primary antibody at $4{ }^{\circ} \mathrm{C}$ overnight. All slides were stained with 3,3'-diaminobenzidine substrate and counterstained with hematoxylin. The Allred score system was used to evaluate the staining results $[13,14]$. The intensity score was graded on scale from 0 to 3 ( 0 for no staining, 1 for weak staining, 2 for moderated staining, and 3 for strong staining). The proportion score was graded on a scale from 0 to 5 ( 0 for no staining, 1 for $\geq 1 \%, 2$ for $\geq 10 \%, 3$ for $\geq$ $33.3 \%, 4$ for $\geq 66.7 \%$, and 5 for $100 \%$ ). The Allred score (range 0 to 8$)=$ intensity score + proportion score. Data were evaluated by a single experienced hepatopathologist who was blinded to the clinical data.

\section{Western blot analysis}

Cancerous or adjacent non-cancerous liver tissue from 30 patients with $\mathrm{HCC}$, or primary human hepatocytes, was lysed in RIPA buffer. Nuclear extracts were harvested using the Nuclear Extraction Kit (Chemicon
International Inc., Billerica, MA, USA). Proteins were resolved on sodium dodecyl sulfate-polyacrylamide gel and electrotransferred onto polyvinylidene fluoride membranes. After blocking in 5\% (w/v) bovine serum albumin or dry milk in Tris-buffered saline with $0.1 \%$ Tween 20 , the membranes were incubated with primary antibody at $4^{\circ} \mathrm{C}$ overnight. After washing, the membranes were incubated with horseradish peroxidase-conjugated goat anti-mouse or anti-rabbit antibody. Signals were detected using a BioSpectrum Imaging System (UVP LLC, Upland, CA, USA). Full immunoblots are shown in Supplementary Figure S2.

\section{Cell cycle analysis}

Following lentiviral transduction, primary human hepatocytes were fixed in $70 \%$ ethanol at $-20^{\circ} \mathrm{C}$ overnight and treated with ribonuclease $\mathrm{A}(50 \mu \mathrm{g} / \mathrm{mL})$ at $37^{\circ} \mathrm{C}$ for 30 minutes. The cells were then stained with propidium iodide $(20 \mu \mathrm{g} / \mathrm{mL})$ and then analyzed by flow cytometry (FACScan, Becton, Dickinson and Company, Franklin Lakes, NJ, USA).

\section{Enzyme-linked immunosorbent assays}

Serum cytokines including interleukin (IL)-1 $\beta$, IL-6, IL-17A, and tumor necrosis factor (TNF)- $\alpha$ were detected using the Ready-Set-Go ELISA kit (eBioscience, San Diego, CA, USA) according to the manufacturer's instructions.

\section{Statistical analysis}

SPSS 17.0 for Windows was used for all statistical analyses. Continuous variables were compared using Student $t$ tests or Mann-Whitney $U$ tests for two independent groups, and paired $t$ tests or Wilcoxon signedrank tests for two related groups. Nominal variables were compared using Fisher's exact tests or Pearson Chi square tests. Multivariate Cox regression analyses were performed to evaluate factors associated with HCC recurrence. Kaplan-Meier analyses and log-rank tests were used to assess the significance of various clinical features on recurrence-free survival or overall survival. Significance was defined as $P<0.05$, and all $P$-values were two-tailed.

\section{ACKNOWLEDGMENTS}

We are grateful for supports from the Human Biobank, Research Center of Clinical Medicine, National Cheng Kung University Hospital and the National RNAi Core Facility, Academia Sinica, Taiwan. We thank Dr. WenYa Huang and Dr. Pai-Sheng Chen from the Department of Medical Laboratory Science and Biotechnology, College of Medicine, National Cheng Kung University, Tainan, Taiwan, for providing critical feedback. 


\section{CONFLICTS OF INTEREST}

All authors declare that there are no conflicts of interest.

\section{GRANT SUPPORT}

This work was supported by grant NCKUH-10204015 from the National Cheng Kung University Hospital, by grant MOST 103-2314-B-006-013-MY3 from the Ministry of Science and Technology, Taiwan, and by grants IM105-PP-01 and IM-105-SP-01 from the National Health Research Institutes, Taiwan.

\section{REFERENCES}

1. Jemal A, Bray F, Center MM, Ferlay J, Ward E, Forman D. Global cancer statistics. CA Cancer J Clin. 2011; 61: 69-90.

2. El-Serag HB. Epidemiology of viral hepatitis and hepatocellular carcinoma. Gastroenterology. 2012; 142: 1264-1273 e1261.

3. El-Serag HB. Hepatocellular carcinoma. N Engl J Med. 2011; 365: 1118-1127.

4. Llovet JM, Bru C, Bruix J. Prognosis of hepatocellular carcinoma: the BCLC staging classification. Semin Liver Dis. 1999; 19: 329-338.

5. European Association for the Study of the Liver, European Organisation for Research and Treatment of Cancer. EASL-EORTC clinical practice guidelines: management of hepatocellular carcinoma. J Hepatol. 2012; 56: 908-943.

6. Portolani N, Coniglio A, Ghidoni S, Giovanelli M, Benetti A, Tiberio GA, Giulini SM. Early and late recurrence after liver resection for hepatocellular carcinoma: prognostic and therapeutic implications. Ann Surg. 2006; 243: 229-235.

7. Shah SA, Cleary SP, Wei AC, Yang I, Taylor BR, Hemming AW, Langer B, Grant DR, Greig PD, Gallinger S. Recurrence after liver resection for hepatocellular carcinoma: risk factors, treatment, and outcomes. Surgery. 2007; 141: 330-339.

8. Diener K, Wang XS, Chen C, Meyer CF, Keesler G, Zukowski M, Tan TH, Yao Z. Activation of the c-Jun $\mathrm{N}$-terminal kinase pathway by a novel protein kinase related to human germinal center kinase. Proc Natl Acad Sci U S A. 1997; 94: 9687-9692.

9. Duan Y, Li F, Tan K, Liu H, Li Y, Liu Y, Kong X, Tang Y, Wu G, Yin Y. Key mediators of intracellular amino acids signaling to mTORC1 activation. Amino Acids. 2015; 47: 857-867.

10. Yan L, Mieulet V, Burgess D, Findlay GM, Sully K, Procter J, Goris J, Janssens V, Morrice NA, Lamb RF. PP2A T61 epsilon is an inhibitor of MAP4K3 in nutrient signaling to mTOR. Mol Cell. 2010; 37: 633-642.

11. Lam D, Dickens D, Reid EB, Loh SH, Moisoi N, Martins LM. MAP4K3 modulates cell death via the post-transcriptional regulation of $\mathrm{BH} 3$-only proteins. Proc Natl Acad Sci U S A. 2009; 106: 11978-11983.

12. Chuang HC, Lan JL, Chen DY, Yang CY, Chen YM, Li JP, Huang CY, Liu PE, Wang X, Tan TH. The kinase GLK controls autoimmunity and NF- $\mathrm{BB}$ signaling by activating the kinase PKC- $\theta$ in $\mathrm{T}$ cells. Nat Immunol. 2011; 12: 1113-1118.

13. Allred DC, Harvey JM, Berardo M, Clark GM. Prognostic and predictive factors in breast cancer by immunohistochemical analysis. Mod Pathol. 1998; 11: 155-168.

14. Harvey JM, Clark GM, Osborne CK, Allred DC. Estrogen receptor status by immunohistochemistry is superior to the ligand-binding assay for predicting response to adjuvant endocrine therapy in breast cancer. J Clin Oncol. 1999; 17: 1474-1481.

15. Chen DY, Chuang HC, Lan JL, Chen YM, Hung WT, Lai KL, Tan TH. Germinal center kinase-like kinase (GLK/ MAP4K3) expression is increased in adult-onset Still's disease and may act as an activity marker. BMC Med. 2012; 10: 84-93.

16. Ramjaun AR, Angers A, Legendre-Guillemin V, Tong $\mathrm{XK}, \mathrm{McPherson}$ PS. Endophilin regulates JNK activation through its interaction with the germinal center kinase-like kinase. J Biol Chem. 2001; 276: 28913-28919.

17. Findlay GM, Yan L, Procter J, Mieulet V, Lamb RF. A MAP4 kinase related to Ste20 is a nutrient-sensitive regulator of mTOR signalling. Biochem J. 2007; 403: 13-20.

18. Karin M, Cao Y, Greten FR, Li ZW. NF-kappaB in cancer: from innocent bystander to major culprit. Nat Rev Cancer. 2002; 2: 301-310.

19. Karin M. NF-kappaB as a critical link between inflammation and cancer. Cold Spring Harb Perspect Biol. 2009; 1: a000141.

20. Ben-Neriah Y, Karin M. Inflammation meets cancer, with NF-kB as the matchmaker. Nat Immunol. 2011; 12: 715-723.

21. Karin M. Nuclear factor-kappaB in cancer development and progression. Nature. 2006; 441: 431-436.

22. Kim HJ, Hawke N, Baldwin AS. NF-kappaB and IKK as therapeutic targets in cancer. Cell Death Differ. 2006; 13: 738-747.

23. Perkins ND. The diverse and complex roles of NF- $\mathrm{B}$ subunits in cancer. Nat Rev Cancer. 2012; 12: 121-132.

24. Joyce D, Albanese C, Steer J, Fu M, Bouzahzah B, Pestell RG. NF-kappaB and cell-cycle regulation: the cyclin connection. Cytokine Growth Factor Rev. 2001; 12: 73-90.

25. Beg AA, Baltimore D. An essential role for NF-kappaB in preventing TNF-alpha-induced cell death. Science. 1996; 274: 782-784.

26. Van Antwerp DJ, Martin SJ, Kafri T, Green DR, Verma IM. Suppression of TNF-alpha-induced apoptosis by NF-kappaB. Science. 1996; 274: 787-789. 
27. Huang S, Pettaway CA, Uehara H, Bucana CD, Fidler IJ. Blockade of NF-kappaB activity in human prostate cancer cells is associated with suppression of angiogenesis, invasion, and metastasis. Oncogene. 2001; 20: 4188-4197.

28. Elsharkawy AM, Mann DA. Nuclear factor-kappaB and the hepatic inflammation-fibrosis-cancer axis. Hepatology. 2007; 46: 590-597.

29. Yokoo H, Yasuda J, Nakanishi K, Chuma M, Kamiyama T, Todo S, Hirohashi S, Sakamoto M. Clinicopathological significance of nuclear factor- $\kappa \mathrm{B}$ activation in hepatocellular carcinoma. Hepatol Res. 2011; 41: 240-249.

30. Li W, Tan D, Zenali MJ, Brown RE. Constitutive activation of nuclear factor-kappa B (NF-kB) signaling pathway in fibrolamellar hepatocellular carcinoma. Int J Clin Exp Pathol. 2009. 3: 238-243.

31. Song R, Song H, Liang Y, Yin D, Zhang H, Zheng T, Wang J, Lu Z, Song X, Pei T, Qin Y, Li Y, Xie C, et al. Reciprocal activation between ATPase inhibitory factor 1 and NF- $\kappa \mathrm{B}$ drives hepatocellular carcinoma angiogenesis and metastasis. Hepatology. 2014; 60: 1659-1673.

32. Kitamoto M, Nakanishi T, Kira S, Kawaguchi M, Nakashio R, Suemori S, Kajiyama G, Asahara T, Dohi $\mathrm{K}$. The assessment of proliferating cell nuclear antigen immunohistochemical staining in small hepatocellular carcinoma and its relationship to histologic characteristics and prognosis. Cancer. 1993; 72: 1859-1865.

33. Suehiro T, Matsumata T, Itasaka H, Yamamoto K, Kawahara N, Sugimachi K. Clinicopathologic features and prognosis of resected hepatocellular carcinomas of varied sizes with special reference to proliferating cell nuclear antigen. Cancer. 1995; 76: 399-405.

34. Ng IO, Lai EC, Fan ST, Ng M, Chan AS, So MK. Prognostic significance of proliferating cell nuclear antigen expression in hepatocellular carcinoma. Cancer. 1994; 73: 2268-2274.

35. Llovet JM, Ricci S, Mazzaferro V, Hilgard P, Gane E, Blanc JF, de Oliveira AC, Santoro A, Raoul JL, Forner A, Schwartz M, Porta C, Zeuzem S, Bolondi L, et al. Sorafenib in advanced hepatocellular carcinoma. N Engl J Med. 2008; 359: 378-390.

36. Bruix J, Takayama T, Mazzaferro V, Chau GY, Yang J, Kudo M, Cai J, Poon RT, Han KH, Tak WY, Lee HC, Song $\mathrm{T}$, Roayaie S, et al. Adjuvant sorafenib for hepatocellular carcinoma after resection or ablation (STORM): a phase 3, randomised, double-blind, placebo-controlled trial. Lancet Oncol. 2015; 16: 1344-1354. 